\title{
Distinguishing Between Depression and Dementia in the Elderly: A Review of Neuropsychological Findings
}

\author{
Greg J. Lamberty and Linas A. Bieliauskas \\ Neuropsychology Program, University of Michigan Hospitals \\ Ann Arbor, Michigan
}

\begin{abstract}
Distinguishing between cognitive deficits seen in depression and progressive dementing diseases is complex and often difficult clinically. We review recent neuropsychological studies comparing normal elderly individuals, depressed patients, and patients with progressive dementias. Findings from these studies suggest that the distinction between depression and dementia is fairly straightforward and facilitated by neuropsychological evaluation. Data from neumimaging studies of depressed elderly are reviewed and integrated with the neuropsychological findings. A descriptive scheme for categorizing elderly patients is proposed. It is suggested that the label "pseudodementia" be discarded in favor of more thorough description of cognitive deficits associated with various clinical presentations.
\end{abstract}

Reversible causes of global cognitive decline were first addressed at length by Kiloh (1961); the term "pseudo-dementia" was used to describe cognitive impairment that could be relieved by appropriate treatment of the acute condition underlying it. "Pseudodementia" (PDEM) has since been used to describe an acquired deterioration of cognitive function - kindred to the deficits seen in primary dementing diseases (PDD) - whose etiology and subsequent course is reversible (Caine, 1981, 1986; Lishman, 1987; Wells, 1979). The origin of such a decline can be varied (acute psychotic reactions, hysterical neuroses, systemic illness, intracranial infections, neoplasms, exposure to toxic agents, medication toxicity, etc.), but there is consistent agreement that the most common of all causes of PDEM is functional psychiatric illness; in particular major depressive disorder (Caine, 1981, 1986; Cummings, Benson,

Address requests for reprints to Greg J. Lamberty, PhD, Psychology Service (116B), Department of Veterans Affairs Medical Center, Iowa City, IA 52246. 
\& LoVerme, 1980; Feinberg \& Goodman, 1984; Folstein, \& McHugh, 1978; Kiloh, 1961; Lishman, 1987; McAllister, 1983; Wells, 1979). However, Kiloh (1961) asserted that PDEM "can of course have no place in any nosological system; it is purely descriptive and carries no diagnostic weight" (p. 336). In spite of this warning, many researchers and practitioners have used the term as a "pseudo-diagnosis" (e.g., Feinberg \& Goodman, 1984; Lishman, 1987), endowing it with etiologic and prognostic ramifications beyond the proposed original descriptive purpose.

Clinically, PDEM has become synonymous with the cognitive deficits seen in patients with major depressive disorder. Caine (1986) characterizes patients with such "neuropsychiatric disorders" as having deficits in the following areas:

(1) arousal, attention, and concentration; (2) mood and affect; (3) perception (both ideational and physical, internal and external); (4) specific intellectual functions (e.g., memory, language); and (5) personality. (p. 221)

While many reviews have described patterns of cognitive dysfunction in depression (cf. Cassens, Wolfe, \& Zola, 1990), most have been plagued by data that are largely anecdotal in nature (case reports), small sample sizes, and poor quantification of specific domains of cognitive function. Historically, neuropsychology has taken a descriptive approach to neurobehavioral function being not so much concerned with naming disorders as it has been with characterizing them. Thus, the advent and propagation of PDEM as a diagnostic label has been frustrating to those concerned with the description of cognitive deficits seen in various neuropsychiatric disorders.

In the case of young adults, the distinction between functionally related cognitive deficits and those hastened by primary degenerative diseases is not typically difficult. However, the diagnostic picture is complicated considerably with elderly patients. Effects of "normal aging" on cognitive function, multiple health problems, and the common use of several different medications are but a few of the factors obscuring appropriate diagnosis of neurobehavioral dysfunction in the aged. The importance of the ability to distinguish between primary dementing processes and functional disorders has been underscored many times. The timely recognition and treatment of depression in the elderly can save a patient from needless suffering and neglect resulting from the hopelessness engendered by a diagnosis of a PDD.

Kaszniak (1987) argues that there are several factors which complicate the dementia/depression distinction. He claims that differentiation between these two clinical states is difficult because: 1) cognitive changes in the elderly blur the distinction between normal aging and early signs of PDD;2) cognitive impairment frequently accompanies depression and can be severe enough to cause confusion between dementia and depression; 3) signs of some neurolog- 
ic diseases associated with progressive decline (e.g., Alzheimer's disease $[A D]$ and Parkinson's disease [PD]) have symptoms that overlap with depression; and 4) dementia and depression can co-exist. The track record of primary care personnel in appropriate diagnosis of dementing disorders has been found lacking in several studies that report high rates of both false-positive and false-negative errors (Garcia, Reding, \& Blass, 1981; Heston, \& Mastri, 1982; McCartney, 1986; National Institute of Aging [NIA] Task Force, 1980; Risse, Raskind, Nochlin, \& Sumi, 1990; Ron, Toone, Garralda, \& Lishman, 1979), pointing to the necessity for improved clinical diagnostic techniques.

In his review of the literature on PDEM, Caine (1986) laments the paucity of well controlled neuropsychological studies with normal aged (21-50 year old range) and elderly adults. While this criticism was true several years ago, there has been an impressive proliferation of studies examining neuropsychological function of depressed patients since that time. In this review we will examine current studies comparing elderly depressed patients, non-depressed patients, and patients with dementia with respect to their performance on various neuropsychological measures. We will also integrate current findings from neuroimaging studies of depressed, elderly patients. Our goal is to clarify the relationship between depression and dementia in the elderly, via standard neuropsychological measures. Finally, we will propose an alternative classification scheme that relies on description of cognitive function and not on a concept such as "pseudodementia".

\section{SCREENING FOR DEPRESSION IN THE ELDERLY}

A fundamental question regarding the generalizability and relevance of studies examining dementia and depression in the elderly has to do with how clinical symptoms are assessed. There arc numcrous brief inventories and checklists for the assessment of depressive symptoms. Most commonly employed among these are the Geriatric Depression Scale (GDS; Yesavage et al., 1983), Mini-Mult Depression Scale (MMD; Kincannon, 1968), Brief Symptom Inventory (BSI; Derogatis, \& Melisaratos, 1983) and the Beck Depression Inventory (BDI; Beck, Ward, Mendelson, Mock, \& Erbaugh, 1961). The relative brevity and self-report nature of these instruments make them easy to administer and fairly reliable. However, these same qualities often raise questions about validity. They presuppose the patient's ability to accurately respond to survey items and often fail to assess a broad enough range of affective and neurovegetative symptoms. For this reason some studies have opted to use the DSM-III guidelines (American Psychiatric Association [APA], 1980) or Research Diagnostic Criteria (RDC; Spitzer, Endicott, \& Robins, 1978) for major depression and dysthymia as more thorough and accurate indicators of depression. Recent work by Harper and colleagues (Harper, Kirby, \& Kotik-Harper, 1986; Harper, Kotik-Harper, \& 
Kirby, 1990), suggests that psychometric instruments like the GDS, MMD, and the BSI may underestimate the presence of depressive illness in the elderly. Other studies using these instruments with the elderly have suggested elevated rates of depressive symptoms (Hale, Cochran, \& Hedgepeth, 1984; Schnurr, Hoaken, \& Jarrett, 1976). In general, it appears that there is almost always a risk of misclassifying patients' clinical presentation if only selfreport measures are used. The problem is particularly troubling when patients fall in a borderline range. Several of the studies cited in this review have compensated for this problem by using self-rating scales as well as clinician ratings based on objective criteria (e.g., DSM-III, RDC).

\section{PREVALENCE OF DEPRESSION AND DEMENTIA IN THE ELDERLY}

Community surveys of the elderly have indicated prevalence rates of affective disorders generally consistent with those found in young adults (Newmann, 1989; Gatz \& Hurwicz, 1990), or even less prevalent (Weissman $\&$ Myers, 1978). The occurrence of depressive symptoms seems to be fairly high in the elderly, ranging from 5 to $40 \%$, but generally found to be around 12-15\%, depending on the method of measurement (Blazer \& Williams, 1980; Gatz \& Hurwicz, 1990; Hertzog, VanAlstine, Usala, Hultsch, \& Dixon, 1990; Snowdon, 1990). Major depression, on the other hand, is considerably less common in the elderly and ranges from 1 to $4 \%$, similar to rates found in the general population (Gatz \& Hurwicz, 1990; Newmann, 1989; Parmelee, Katz, \& Lawton, 1989). More pertinent is the observation that several sub-populations of elderly patients tend to show marked increases in depressive symptomatology when compared to community dwelling cohorts. Recent work shows considerably elevated levels of major depression $(12.4 \%$ as measured by DSM-III-R criteria), as well as a high degree of depressive symptomatology $(30.5 \%)$ in elderly patients who are institutionalized (Parmelee et al., 1989). These levels are important because they are likely more representative of the elderly sample that presents for evaluation of cognitive dysfunction.

Some degree of cognitive impairment is recognized as a normal concomitant of aging (Kramer, German, Anthony, VonKorf, \& Skinner, 1985; Myers et al., 1984; Robins et al., 1984), though the exact nature and extent of this impairment is described variably. A recent study examining the prevalence of AD and other dementing illnesses in a community setling suggests increasing levels of deficit with increasing age (Evans et al., 1989). Evans et al. (1989) reported an overall prevalence rate of $10.3 \%$ for probable Alzheimer's disease for community dwelling individuals over 65 years of age. Other causes of cognitive deficit were considerably less common and included multiple cerebral infarcts, alcoholic dementia, PD, and various reversible causes. Epidemiological studies sampling a broader range of elderly patients indicate 
higher prevalence rates for AD. For instance, Pfeffer, Afifi, and Chance (1987) found a prevalence rate of $15.3 \%$ for $A D$ in patients aged 65 and over in a retirement community population.

Several studies have examined the coexistence of depressive symptoms and cognitive deficits (Kral \& Emery, 1989; Reding, Haycox, \& Blass, 1985; Reifler, Larson, \& Hanley, 1982). For instance, Reifler et al. (1982) reported major depression in $23 \%$ of a sample of cognitively impaired individuals referred to an outpatient geriatric clinic. Most $(85 \%)$ of the depressed patients were also demented. The rate of depression decreased markedly with increasing cognitive impairment (Reifler et al., 1982), though Kaszniak and colleagues have found no relationship between the severity of dementia and depression in their samples (Kaszniak, 1985; Kaszniak, Wilson, Lazarus, Lessor, \& Fox, 1981). Lazarus, Newton, Cohler, Lesser, and Schweon (1987) evaluated patients with primary degenerative dementia for the presence of depressive symptoms and reported that $40 \%$ of their patients demonstrated at least mild depressive symptoms as compared to $12 \%$ of a comparison group of normal elderly.

An important question concerns the prognosis of elderly patients who present with depressive symptoms. A report by Reding et al. (1985) suggests that a high percentage of patients $(57 \%)$ presenting with depression go on to develop a "frank dementia." However, these researchers acknowledge that most of these patients had some signs of organic neurological disease upon initial examination. These authors identify a number of risk factors for the subsequent development of dementia including:

evidence of cerebrovascular, extrapyramidal, or spinocerebellar disease; a modified Hachinski ischemic score of 4 or greater; a Mental Status Questionnaire score of under 8; a dementia behavior score of 7 or higher; or confusion on low doses of tricyclic antidepressants. (p. 894)

Kral and Emery (1989) assert even more forcefully the relationship between patients presenting with "reversible dementia" and subsequent dementing illness. Fully $89 \%$ of their depressive pseudodementia sample was diagnosed with Alzheimer-type dementia over long follow-up intervals (average 8 years).

It should be noted that there is a natural bias toward increased psychological and cognitive difficulties in such clinic patients by virtue of their presentation as patients in the first place. Also, the methods of diagnosing dementia in both of the studies cited above are not well specified. Methodological and selcction procedures notwithstanding, there is growing evidence from the field of neuroimaging that depressed elderly patients show relatively greater cerebral findings as compared to normal elderly cohorts. For example, a recent study by Nussbaum, Kaszniak, Allender and Rapcsak (1991) which fullowed 
elderly patients initially referred for depression, found that $23 \%$ ( 8 of 35 ) of a sample of depressed patients demonstrated cognitive decline (decline of 4+ points on the MMSE) when re-examined an average of 25 months following the initial evaluation. The sample in this study was different by virtue of the fact that they were given a primary diagnosis of depression, with no evidence of dementia. Those depressed patients with greater white matter abnormalities on MRI were more likely to show cognitive decline. This study indicates a positive relationship between cognitive decline and neuroimaging abnormalities, which should not be surprising. However, the question that needs to be addressed more thoroughly is the degree to which cerebral pathology is associated with depression. The next section deals with studies examining cerebral changes in patients with major depression.

\section{IMAGING FINDINGS}

A recent review on imaging and affective disorders in the elderly points to a number of consistent findings (Morris \& Rapoport, 1990). Computerized axial tomography (CT) studies have indicated more pathological changes in the brains of depressed elderly patients relative to normal elderly controls or young depressed patients. Findings have included ventricular enlargement (Jacoby \& Levy, 1980; Jacoby, Levy, \& Bird, 1981), cortical atrophy (Dolan, Calloway, \& Mann, 1985), decreased brain tissue density (Dolan, Calloway, Thacker, \& Mann, 1986), and "leukoencephalopathy" (white matter changes; Coffey et al., 1988; Coffey, Figiel, Djang, \& Weiner, 1990). Morris and Rapoport (1990) note that while these findings are consistent across many studies, there is a dearth of appropriately controlled research allowing firm differential diagnoses. In contrast to the studics noted above, Wilson, Fox, Huckman, Bacon, and Lobick (1982) found that CT density information did not aid in making the distinction between normals and patients with dementia. They noted wide variability among elderly patients in various clinical and normal groups (with respect to CT density findings) and suggested that clinical correlation was essentially lacking.

A unique study by Pearlson et al. (1989) compared CT scans of patients with probable $A D$, normal elderly individuals, and patients referred for treatment of major depression. A subset of these patients improved cognitively following treatment and were thus classified as evidencing the "dementia syndrome of depression" (DOD; Folstein \& McHugh, 1978). Ventricular brain ratio (VBR) and CT attenuation numbers showed that depressed patients fell between normal and $\mathrm{AD}$ patients with respect to these indices of cerebral pathology. Interestingly, the DOD subgroup looked qualitatively more like the AD patients, whereas depressed, cognitively normal patients were more similar to the normal elderly group. In contrast to the findings of the studies noted 
earlier (Kral \& Emery, 1989; Reding et al., 1985), DOD patients did not evidence advancement of cognitive deficits upon follow-up examination.

Magnetic resonance imaging (MRI) scans are more sensitive to subtle subcortical changes than are CT images and are also able to verify the volume loss and cortical changes seen on CT scans (Morris \& Rapoport, 1990). Studies by Coffey and his colleagues (Coffey et al., 1988, 1990; Coffey, Figiel, Djang, \& Saunders, 1989) have examined changes in periventricular white matter (PWM) in normal and depressed elderly patients. "Hyperintensities" in PWM and deep white matter (DWM) are common in most elderly subjects, but are considerably more extensive and severe in depressed elderly patients. In addition, subcortical gray matter (e.g., thalamus, basal ganglia) abnormalities are generally more extensive in depressed patients (Coffey et al., 1990; Kertesz, Polk, \& Carr, 1990). Work by Dupont and colleagues $(1987,1990)$ has shown that young adult patients with bipolar disorder are more likely to show subcortical signal hyperintensities than demographically matched non-psychiatric controls. Thus, the finding of greater subcortical pathology on MRI scans for depressed patients is not unique to the elderly.

A recent study by Grafton et al. (1991) found little correlation between DWM abnormalities on MRI and actual postmortem neuropathology. Their findings call into question the relevance of trying to distinguish between elderly patient groups based on MRI findings of DWM abnormalities. Along these lines, Morris and Rapoport (1990) emphasize difficulties with the interpretation of imaging data due to inadequate matching of patient groups on vascular risk factors and various other demographic factors. It has been speculated that the etiology of hyperintensities may be sccondary to arteriosclerotic disease of the small vessels that supply the subcortical regions of the brain (Coffey et al., 1988), or "reactive gliosis following a variety of insults" (Morris \& Rapoport, 1990). The absolute clinical significance of subtle white matter and subcortical nuclei changes in the elderly, as seen on MRI, is far from well characterized and will doubtless be the major focus of future studies.

\section{NEUROPSYCHOLOGICAL FINDINGS}

The effects of depression and aging on cognitive function have most commonly been studied by examining memory. It is widely acknowledged that memory complaints increase with age (cf. Kahn, Zarit, Hilbert, \& Niederehe, 1975; Popkin, Gallagher, Thompson, \& Moore, 1982), although the relationship between increased complaints and actual memory dysfunction is less than well-established. Studies examining memory function in depression have taken two general approaches. Some researchers have employed memory assessment techniques and theories culled from the experimental psychology literature (Hart \& Kwentus, 1987; Miller \& Lewis, 1977; Niederehe, 1986; 
Niederehe \& Camp, 1985; Sternberg \& Jarvik, 1976; Weingartner, Cohen, Murphy, Martello, \& Gerdt, 1981; Whitehead, 1973), while others have examined performance on standardized clinical instruments (Hart, Kwentus, Hamer, \& Taylor, 1987; Hart, Kwentus, Wade, \& Hamer, 1987; La Rue, 1989; La Rue, D'Elia, Clark, Spar, \& Jarvik, 1986). General findings from the studies noted in this review are outlined in summary form in Table 1.

While clinical instruments often lack the theoretical elegance of experimental methods, they have proven invaluable in differentiating between normal and pathological states. Conversely, cognitive models have been less successful in demonstrating relationships between clinical states and theoretical processes. The search for "double dissociations" - wherein patient and normal comparison groups perform in fundamentally different ways on cognitive tasks purported to measure specific attributes of the memory process - has been only minimally successful. In the clinical setting, there appears to be growing interest in the "information-processing" approach to cognitive function (Kaszniak, Poon, \& Riege, 1986). Yet, experiments utilizing such methodology with clinical groups of elderly patients have been limited.

Early work by Whitehead addressed the issue of verbal learning and memory deficits in depression by comparing elderly depressed and patients with mild dementia (Whitehead, 1973), and "ill" and "well depressives"

TABLE 1

Summary of Cognitive Findings for Depressed and Primary Progressive Dementia Patlents

\begin{tabular}{ll}
\hline Cognitive Domain & Depressed vs. Normal Patients \\
\hline $\begin{array}{l}\text { Neuropsychological } \\
\text { batteries }\end{array}$ & $\begin{array}{l}\text { Small differences between depressed } \\
\text { and normal patients. Most prominent } \\
\text { differences exist for motor-related } \\
\text { tasks and attention. }\end{array}$
\end{tabular}

New learning ability Mild attentional difficulty, "shallow" (immediate memory) encoding of information, decreased response latency, adequate encoding of information with serial presentation of material.

Memory (retention)

Near normal rate of forgetting on delayed recall testing, with recall not significanty different from that of normal patients.

Language function
Essentially normal receptive and expressive abilities. Reduced verbal fuency.
PDD vs. normal Patients

Substantial deficits as compared to normals. Less differentiation between PDD and depressed patients on attentional and motor-related tasks.

Moderate to severe attentional difficulty, lack of ability to systematically encode information, essentially random learning with litule benefit from serial presentation of materials.

Accelerated rate of forgetting on delayed recall testing with essentially no retention following a delay. Deficient immediate recall.

Decline in expressive and receptive skills as a function of stage of progression. 
(Whitehead, 1974). Whitehead's (1974) findings indicated that, relative to treated depressed patients, non-treated patients showed mild verbal learning impairment. However, such deficits were subtle as compared to differences noted between non-treated depressed patients and patients with mild dementia. The nature of the differences between depressed and mild dementia patients was posited to be due to varied response strategies (Whitehead, 1973). Depressed patients tended to show less random variation in their responses, taking a more "conservative" approach, whereas patients with mild dementia committed more random and false positive errors (Whitehead, 1973). While Whitehead's findings were based on relatively small samples of patients (e.g., $n=12$ ) with weakly defined clinical diagnoses, Miller and Lewis (1977) verified depressed patient's conservative response strategies with well-matched and more clearly defined samples. They found that depressed patients' accuracy on a recognition memory task was similar to that of normal controls and significantly better than that of PDD patients. Niederehe (1986) reported a series of studies aimed at distinguishing between depressed, PDD patients, and normals on measures of "episodic", "semantic" (Tulving, 1972), and constructive memory. He found few significant differences between depressed and normal subjects with the exception of the conservative response bias noted above and evidence of mild attentional difficulty. Niederehe's (1986) studies, based on small $(n=24)$, well-matched groups, consistently showed PDD patients performing at a qualitatively worse level than depressed groups.

Experimental evaluations of memory phenomena have often focused on deficits in particular "stages" of the memory process (Atkinson \& Shiffrin, 1968). Within the context of a "levels of processing" approach (Craik \& Lockhart, 1972) depressed patients might not encode information to the same "depth" as normal subjects. Weingartner et al. (1981) examined normal (n $=10)$ and depressed $(n=10)$ subjects' ability to employ elaborative encoding strategies when learning new information. Their findings suggested that depressed patients failed to engage in encoding strategies that would maximize the likelihood of subsequent recall. However, depressed patients were able to benefit when material was presented in an already organized fashion. Taking a slightly different tack, Weingartner (1986) looked at depressed patients' encoding abilities as a function of the relative amount of effort expended in initial learning (Hasher \& Zacks, 1979). He found that depressed patients were less successful than normals when engaging in "effort demanding" encoding exercises. Thus, Weingartner (1986) posited, "biological systems associated with motivation, effort, and arousal... appear to be linked to the performance of effortdemanding cognitive operations in depressed patients" (p. 223). As with the studies mentioned above, Weingartner's investigations were based on small, but well-characterized samples. Findings across studies using more "experimental" approaches have been fairly consistent despite the small sample sizes. 
Clinical researchers have access to populations that might reveal the actual "biological systems" involved in memory processes. Hart and Kwentus (1987) examined memory scanning and incidental memory performance in depressed elderly $(n=15)$ and normal control patients $(n=16)$. They employed the Sternberg task (ST; Sternberg, 1975) and the digit symbol (DS) subtest of the WAIS-R (Wechsler, 1981). Both of these tasks emphasize rapid performance and are measures of basic psychomotor speed, as well as incidental memory (DS) and information processing efficiency (ST). Hart and Kwentus (1987) found depressed patients' reaction time to be significantly slowed. However, incidental memory for symbols (on DS) and information processing capacity (slope function of the ST) were not affected by depressive status. The psychomotor slowing noted in depressed patients was likened to that seen in PD (Wilson, Kaszniak, Klawans \& Garron, 1980) and Friedreich's ataxia (Hart, Kwentus, Leshner \& Frazier, 1985). It was interesting however, that information processing capacity was not affected by depression as seen in PD and Friedreich's ataxia. Hart and Kwentus (1987) raised the possibility that the psychomotor slowing in depressed patients was due more to "motivational" factors that are mediated by catecholaminergic systems.

In an attempt to more clearly identify information processing deficits in dementia and depression, Hart, Kwentus, Taylor, and Harkins (1987) employed a strategy suggested previously (Huppert \& Piercy, 1978). Huppert and Piercy (1978) found that patients with Korsakoff's syndrome demonstrated an initial learning deficit, but a normal rate of forgetting. In the Hart, Kwentus, Taylor, et al. (1987) study, depressed patients, AD patients, and normal subjects were equated on initial learning by allowing differential exposure to to-be-remembered information. The patients were presented line drawings for 2,4 , and $8 \mathrm{~s}$ (for normal, depressed, and Alzheimer's patients, respectively), with the understanding that the groups were characterized by varying levels of learning impairment. Their results indicated that depressed and normal individuals forgot information at the same rate, whereas $\mathrm{AD}$ patients showed a much more rapid rate of forgetting. This was in the face of relatively equivalent general intellect, verbal fluency, and concentration ability. Hart, Kwentus, Taylor, et al. (1987) suggested that depressed and AD patients might be distinguished on the basis of how quickly they forget initially encoded information. Along these lines, a recent study by Welsh, Butters, Hughes, Mohs, and Heyman (1991) indicated that the most reliable measure for distinguishing between normal controls and patients with very mild $\mathrm{AD}$, was patients' delayed recall on a 10-word serial word list task. Finally, Dannenbaum, Parkinson, \& Inman (1988) compared depressed $(n=15)$, normal $(n=15)$, and $\mathrm{AD}$ patients' $(n=15)$ performance on a Brown-Peterson task in which subjects were equated for immediate recall. Their findings indicated that depressed subjects' short-term forgetting fell between normal and AD patients' performance. As with other studies, AD patients demonstrated deficits in learning as well as retention, and were easily differentiated from 
depressed elderly. Of the foregoing studies, the Welsh et al. (1991) investigation included the largest $(n=49)$ and most carefully selected groups. Nonetheless, results from all studies show a consistent relationship, wherein depressed patients perform in a manner more similar to that of normal patients as opposed to patients with PDD.

Hart and his colleagues have also looked at memory function in depressed elderly patients using several different standardized clinical instruments. In a study using the incidental memory manipulation with the DS subtest of the WAIS-R (noted above) they found that depressed $(n=15)$ and mildly demented patients $(n=15)$ were similar with respect to psychomotor speed, but depressed patients remembered significantly more symbols than mild $A D$ patients (Hart, Kwentus, Wade, et al., 1987). A study examining memory performance using the selective reminding procedure (Buschke, 1973), produced a similar pattern of results (Hart, Kwentus, Hamer, et al., 1987). That is. depressed patients $(n=14)$ were impaired on total recall and proportion of items retained from trial to trial relative to normals $(n=16)$, but were superior to mild AD patients ( $n=15)$ across all memory indices.

Work by La Rue and collaborators has examined elderly depressed patient's performance on a variety of clinical memory tasks (La Rue, 1989; La Rue et al., 1986). Normal elderly $(n=10)$, depressed patients $(n=10)$, and patients with PDD $(n=10)$ were compared with respect to their performance on the Benton Visual Retention Test (BVRT), Inglis Paired Associate Learning Test (IPA), and Fuld Object Memory Evaluation (OME) (La Rue et al., 1986). Depressed patients performed at or below the level of normal controls on most BVRT and IPA indices, and were generally superior to dementia patients. However, the OME was far better at distinguishing between groups. A discriminant function analysis using the consistent retrieval index from the OME, total correct responses for the IPA mediate pairs, and total errors on the BVRT was conducted to compare healthy/depressed and depressed/demented groups. It was found that all three indices helped to discriminate between normal and depressed individuals, but only the consistent retrieval measure from the OME successfully distinguished depressed and PDD groups (La Rue et al., 1986). In a different study, La Rue (1989) compared depressed patients $(n=41), \mathrm{AD}$ patients $(n=19)$, and patients with other organic impairments (e.g., PD, multi-infarct dementia; $n=20$ ) on the OME. A general finding was that depressed patients performed better than AD patients on "all initial learning and recall measures as well as delayed recall" (p. 420).

While the sample sizes of most of the studies cited are relatively small (generally 10-30 subjects per group), the methodologies vary widely. Nonetheless, both experimental and clinical studies place memory performance for depressed elderly patients between that of normal elderly individuals and patients with mild dementia symptoms. Experimental studies tend to find subtle differences between normal and depressed individuals. Most researchers suggest that such differences represent general cognitive ineffi- 
ciency and attentional problems rather than a fundamental lack of ability due to structural deficits. In contrast, differences between depressed and PDD patients are consistent and significant. Most studies using patients with PDDs select patients with relatively mild symptoms. Even so, marked differences are found, suggesting fundamentally different patterns of cognitive function and underlying pathology.

A number of studies have examined neuropsychological function in depressed patients by employing comprehensive batteries and/or intelligence tests. Gray, Rattan, and Dean (1986), looked at performance of depressed $(n=30)$, PDD $(n=26)$, and general neurological patients $(n=24)$ on subtests of the Halstead-Reitan Neuropsychological Battery (HRB). They found that depressed patients were generally less impaired, as measured by the Halstead impairment index, than PDD and neurological groups. In fact, depressed individuals were superior to the other groups on all HRB measures except, Tactual Performance Test location, Speech Sounds Perception Test, and Trail-Making Test A (Gray et al., 1986). In a similar vein, McCue, Goldstein, and Shelly (1989) compared performance of depressed $(n=45)$ and PDD patients $(n=34)$ on a short form of the Luria Nebraska Neuropsychological Battery (LNNB). They were able to differentiate between the groups on all 10 clinical scales of the form employed. Patients with depression who were misclassified as having PDD tended to have more extreme degrees of depressive symptomatology and lower educational levels (McCue et al., 1989). These studies, with larger sample sizes, a broader range of cognitive domains assessed, and a decidedly more clinical bent, confirm the general finding of substantial differences between depressed and demented individuals.

Bornstcin, Tcrmcer, Longbrakc, Hcgcr, and North (1989), studicd a sample of elderly depressed patients $(n=62)$ for the presence of the "Fuld profile" (Fuld, 1984) on the Wechsler Adult Intelligence Scale-Revised (WAIS-R; Wechsler, 1981). The profile is thought to be relatively specific (though not necessarily sensitive) to disorders in which there is prominent temporal lobe pathology, most notably $\mathrm{AD}$. Results from this study indicated that the Fuld profile was less common in depressed elderly patients (16\%) than in the AD samples reported in 1984 by Fuld (44\%), but similar to that observed in a normal subject group (12.8\%; Satz, VanGorp, Soper \& Mitrushina, 1987). These findings suggest that the Fuld profile may be helpful in distinguishing between depressed elderly patients and those with PDDs (Bornstein et al., 1989).

Quasi-comprehensive screening measures are frequently employed in the evaluation of geriatric patients. Recent work by Bieliauskas and colleagues (Bieliauskas, Costello, \& Terpenning, 1991; Bieliauskas \& Lamberty, 1991; Bieliauskas, Lamberty \& Boczar, 1991) has verified the lack of significant differences between normal and depressed patients on such measures. In a series of studies using screening measures such as the MMSE and the Neurobehavioral Cognitive Status Exam (NCSE; Kiernan, Mueller, Langston, 
\& VanDyke, 1987) no differences were found between depressed ( $n=15)$ and non-depressed patients $(n=33)$ across a wide array of cognitive and motor tasks (with the exception of the NCSE Attention subtest). These studies support the notion that differences between normal and depressed patients are sufficiently subtle to not significantly influence scores on standard cognitive screening instruments.

Only a very small number of studies have specifically examined speech-language function in elderly depressed patients. While most of the above mentioned tasks have obvious receptive and expressive language components, we will discuss a few studies looking at specific language skills. For instance, Emery and Breslau (1989) found that depressed patients $(n=20)$ perform better than AD patients $(n=23$ ) on measures of naming, repetition, general reading skill, syntax, and auditory verbal comprehension. Normal individuals $(n=20$ ) tended to show better language performance than depressed patients overall, though these differences were considerably less obvious than those noted between depressed and AD patients (Emery \& Breslau, 1989). Productive naming or "verbal fluency" tasks are recognized as sensitive indicators of general cognitive impairment and are helpful in distinguishing between normal individuals and those with PDDs (Martin \& Fedio, 1983). However, Hart, Kwentus, Taylor, and Hamer (1988) found that both depressed $(n=17)$ and $\mathrm{AD}$ patients $(n=31)$ showed reduced verbal fluency. There were no differences between depressed and AD patients on the familiar controlled oral word association test (a.k.a., F-A-S; Benton \& Hamsher, 1991), but depressed patients outperformed AD patients on a categorical fluency task (i.e., "animals"). Once again, a reduction in psychomotor speed was invoked to explain depressed patients' weakness on this task (Hart, Kwentus, Taylor, et al., 1988).

Another commonly used measure of language function is the Boston Naming Test (BNT; Kaplan, Goodglass, \& Weintraub, 1983). Using a 30-item version of the BNT, a recent study reported that depressed patients were impaired to the same extent as patients with irreversible dementias (Speedie, Rabins, Pearlson, \& Moberg, 1990). While prominent language deficits (including confrontation naming) are not thought to be common in depression (Caine, 1986), few studies have examined confrontation naming ability specifically. Generally speaking, studies examining cognitive function have looked at language function only incidentally. This is one area that requires much more extensive analysis, such as in the Emery and Breslau (1989) study noted above.

At present, there is still a relatively small body of literature examining the effects of depression on cognitive function in the elderly. In spite of the methodological and sampling problems encountered when working with these complex populations, it is clear that depressed patients can be distinguished from patients in the early stages of progressive dementing illnesses with impressive levels of accuracy. These findings contradict the skepticism 
expressed by various researchers (Caine, 1986; Kiloh, 1961; Wells, 1979) regarding the sensitivity of neuropsychological tests for making these distinctions. Subsequent endeavors in this area must strive to match subject groups more thoroughly with respect to cerebrovascular risk factors, psychiatric history, affective status and general health.

\section{PROPOSED ALTERNATIVES TO “PSEUDODEMENTIA"}

There are a broad range of clinical presentations with respect to depressive symptoms and cognitive function in elderly patients. Several researchers have proposed alternative descriptive schemes for characterizing the clinical features of depression and dementia in elderly patients (Ancill, 1989; Fogel \& Fretwell, 1985; Folstein \& Rabins, 1991; Reifler, 1986). All of these schemes are predicated on a fundamental dissatisfaction with the term pseudodementia as inadequate and generally confusing.

We propose five different patient types beginning with the normal elderly patient (see Table 2). The normal patient shows no or few signs of affective disorder, is within normal limits with respect to his/her cognitive function, and

TABLE 2

Cognitive/Affective Presentations and Imaging Findings in the Elderly

\begin{tabular}{|c|c|c|c|}
\hline Clinical Presentation & Cognitive Function & Affective Symptoms & Imaging Findings \\
\hline normal & within normal limits & within normal limits & $\begin{array}{l}\text { within normal limits } \\
\text { (i.e., mild, diffuse } \\
\text { anomalies) }\end{array}$ \\
\hline $\begin{array}{l}\text { depressed/no cognitive } \\
\text { dysfunction }\end{array}$ & within normal limits & $\begin{array}{l}\text { depressed affect, } \\
\text { anhedonia vegetative } \\
\text { signs, psychomotor } \\
\text { retardation, feelings } \\
\text { of worthlessness, guilt }\end{array}$ & $\begin{array}{l}\text { white matter } \\
\text { hyperintensities, } \\
\text { increased VBR, } \\
\text { decreased tissue } \\
\text { density, mild atrophy }\end{array}$ \\
\hline $\begin{array}{l}\text { depressed/motor- } \\
\text { related cognitive } \\
\text { deficits }\end{array}$ & $\begin{array}{l}\text { mild to moderate } \\
\text { attentional and } \\
\text { encoding deficits, } \\
\text { generally slowed } \\
\text { mentation }\end{array}$ & $\begin{array}{l}\text { same as above, } \\
\text { possibly greater } \\
\text { retardation }\end{array}$ & same as above \\
\hline $\begin{array}{l}\text { depressed/broad } \\
\text { cognitive deficits }\end{array}$ & $\begin{array}{l}\text { pervasive cognitive } \\
\text { deficits (intellect, } \\
\text { memory, language, } \\
\text { conceptual ability, } \\
\text { motor function, etc.) }\end{array}$ & $\begin{array}{l}\text { same as above, } \\
\text { increased agitation, } \\
\text { perturbability }\end{array}$ & $\begin{array}{l}\text { widespread moderate } \\
\text { to severe, atrophy } \\
\text { cortical and sub- } \\
\text { cortical cell loss, } \\
\text { increased VBR }\end{array}$ \\
\hline $\begin{array}{l}\text { not depressed/broad } \\
\text { cognitive deficits } \\
\text { (e.g., AD) }\end{array}$ & same as above & $\begin{array}{l}\text { flatness or lability, } \\
\text { agitation }\end{array}$ & same as above \\
\hline
\end{tabular}


shows only very mild, diffuse anomalies on neuroimaging scans (compared with normal, young adults).

Depressed elderly patients with no appreciable cognitive deficits are essentially normal upon neuropsychological evaluation, as compared with same aged cohorts. These patients show the full spectrum of depressive symptomatology including psychomotor retardation, neurovegetative signs (sleep and appetite disturbance), anhedonia, depressed affect, and feelings of worthlessness and guilt. Imaging findings are quantitatively more severe and include moderate white matter abnormalities, increased ventricle size, decreased tissue density and mild atrophy.

Patients typically referred to as evidencing PDEM demonstrate the same pattern of depressive symptoms noted above. Performance on neuropsychological measures is characterized by motor slowness and weakness, poor attentional ability, and decreased immediate recall of newly presented information. These deficits are markedly worse than those seen in depressed patients without cognitive deficits and normal elderly patients, but easily distinguishable from the deficits seen in progressive dementing conditions. While imaging studies with these patients are limited, there is some suggestion by Pearlson et al. (1989) that they demonstrate CT abnormalities that fall between cognitively normal depressed patients and Alzheimer's disease patients.

Finally, there are two categories of patients with broad-based cognitive deficits (most commonly secondary to $A D$ ). The first group of patients show depressive symptoms as noted, along with increased agitation and petulance. The last group of patients, those with pervasive cognitive deficits only, fail to demonstrate a symptom picture consistent with major depression. Imaging and pathological findings in both of thesc groups show widespread moderate to severe cortical atrophy, subcortical cell loss, and ventriculomegaly.

\section{DEPRESSION AS AN EARLY INDICATOR OF PROGRESSIVE DEMENTING DISORDERS}

Kral and Emery (1989) and Reding et al. (1985) have claimed that a large percentage of depressed patients and patients with PDEM go on to develop a primary progressive dementia. Nussbaum et al. (1991) have also suggested that a subset of patients presenting with depression in late life go on to develop an Alzheimer-type dementia. Given the very few studies examining the extent to which depression progresses to dementia, it is difficult to determine the exact nature of this relationship. Epidemiological studies have not typically examined depression's role in later cognitive decline. Of the few that have looked at psychiatric history there appears to be a positive association between depressive history and AD. For instance, French et al. (1985) found an increased incidence of depression in SDAT patients as compared to hospital 
and normal controls. A similar relationship was reported by Barclay, Kheyfets, Zemcov, Blass, and McDowell (1986).

At this point it would be premature to invoke depression as a major risk factor or early warning sign for the development of a progressive dementia. The studies cited have all involved referrals to dementia or cognitive disorders clinics and therefore represent a biased sample. However, the fact that depression does not necessarily represent a unitary neurobehavioral entity should not be forgotten. The etiology of depression can vary widely from primarily psychological to primarily neurological. It is clear that in many elderly depressed patients there is a preponderance of subcortical and white matter anomalies (Morris \& Rapoport, 1990). This is consistent with the "subcortical" findings of psychomotor retardation and mild to moderate visuomotor deficits in these patients. The relationship between imaging findings and depression is, at present, speculative and tautological in nature. Clearly, more work is needed to elucidate these complex relationships.

It is of critical importance to understand the factors which influence the progression of cognitive deficits in elderly patients. Certainly normal risk factors should be considered (evidence of cerebrovascular disease, hypertension, cardiac problems, behavioral indicators of change, etc.). However, an equally important factor is the extent to which a patient is evaluated with respect to his/her neurobehavioral status. A thorough examination of cognitive and emotional function by a competent neuropsychologist is likely to produce a much more clear picture of the processes involved in a given patient's cognitive decline than is a summary bedside mental status examination. The former would include measurement of a wide range of cognitive skills, psychological functioning, and should involve follow-up to assess the extent of change in status over time.

\section{SUMMARY}

Progressive dementing conditions and major depression can both produce cognitive changes in elderly patients. It seems that the simple case of distinguishing between depression and dementia in a given patient is rarely the singular concern. As we have illustrated, there are a wide range of clinical presentations characterized by varying degrees of cognitive and affective dysfunction. The following points summarize the current state of knowledge in this complex area.

First, cognitive deficits seen in patients with a primary diagnosis of major depression are quite easily distinguishable from the deficits observed in patients with a primary diagnosis of a PDD (e.g., Alzheimer's disease). In other words, pseudodementia is a misnomer which infers that depressed patients present with cognitive deficits that mimic those seen in PDD. In most 
cases, neuropsychological evaluation bears out major quantitative and qualitative differences between these groups. However, brief screening measures such as the Mini-Mental State Examination (Folstein \& McHugh, 1978) may not be sensitive to such differences.

Second, degenerative changes in the brains of elderly depressed subjects suggest greater cerebral pathology than seen in normal patients, although this is not necessarily associated with qualitative changes in cognitive function. White matter abnormalities and degeneration of subcortical nuclei (thalamus, basal ganglia) can produce motor system dysfunction that is often mistaken for, or coincident with, major depression. Findings in neuroimaging point to the need for vigilance when the prospect of depression is raised in an elderly patient. Because depression is measured in so many different ways, the exact correspondence between major depression and cerebral pathology is still unclear. Also, a large number of additional risk factors (cerebrovascular disease, hypertension, diabetes, etc.) obscure the degree of damage attributable to major depression alone.

Third, nonmajor depression does not appear to have significant influence on patients' performance on standard cognitive screening examination measures. Thus, if cognitive deficits are detected by such screens, the probability of PDD is increased and full neuropsychological examination would be well-advised.

Fourth, the coexistence of major depression and progressive cognitive decline can complicate the diagnostic and prognostic picture. Without a thorough evaluation of both cognitive and affective symptoms, patients can be misdiagnosed, with potentially harmful consequences. If the diagnosis of depression is conferred, then the patient is assumed to be "pseudodemented" and important information for the patient/family regarding progression of deficits may be withheld. On the other hand, a diagnosis of a PDD can cause appropriate treatment of depressive symptoms to be withheld and result in needless suffering. As we have indicated, elderly patients typically present with a wide range of symptoms that can be common to many different clinical disorders. Thus, both depression and cognitive decline should be considered in a patient who presents with prominent psychomotor slowing and mood-related problems. It should be noted that patients are too often taken at their word with respect to the symptoms which they present; the need for objective evaluation of both affective and cognitive domains in these patients cannot be overemphasized.

Finally, it is unclear as to whether or not depressive symptoms are a harbinger of PDD, with the answer awaiting further research. Careful attention will need to be paid to cerebrovascular and other health-related risk factors when advising patients and families about the future and in designing the necessary prospective studies. A top priority should be increasing the accuracy of prediction with respect to which patients will progress to dementing diseases. With continued attention to careful research design and cooperation among 
disciplines, the next few years promise to add much to our knowledge of the relationship between depression and dementia in the elderly.

\section{REFERENCES}

American Psychiatric Association. (1980), Diagnostic and statistical manual of mental disorders (3rd ed.). Washington, DC: Author.

Ancill, M. B. (1989). Cognitive-affective disorders: The co-presentation of depression and dementia in the elderly. Psychiatric Journal of the University of Ottawa, 14, 370-371.

Atkinson, R. C. \& Shiffrin R. M. (1968). Human memory: A proposed system and its control processes. In K. W. Spence \& J. T. Spence (Eds.), Advances in the psychology of learning and motivation research and theory (Vol. II). New York: Academic Press.

Barclay, L. L., Kheyfets, S., Zemcov, A., Blass, J. P., \& McDowell, F. H. (1986). Risk factors in Alzheimer's disease. In A. Fisher, I. Hanin, \& C. Lachman (Eds.), Alzheimer's and Parkinson's Disease (pp. 141-146). New York: Plenum Press.

Beck, A. T., Ward, C. H., Mendelson, M., Mock, J., \& Erbaugh, J. (1961). An inventory for measuring depression. Archives of General Psychiatry, 40, 569-573.

Benton, A. L., \& Hamsher, K. deS. (1991). The Multilingual Aphasia Exam. Iowa City, IA: AJA Associates.

Bieliauskas, L. A., Costello, S., \& Terpenning, M. (1991). Depression and screening for cognitive deficit in elderly patients. Journal of Clinical and Experimental Neuropsychology, 13, 101.

Bieliauskas, L. A., \& Lamberty, G. J. (1991). Simple reaction time and depression in the elderly. The Clinical Neuropsychologist, 5(3), 252.

Bieliauskas, L. A., Lamberty, G. J., \& Boczar, J. (1991). Lack of depression effects on cognitive function in the elderly. Journal of Clinical and Experimental Neuropsychology, 13(3), 433.

Blazer, D., \& Williams, C. D. (1980). Epidemiology of dysphoria and depression in an elderly population. American Joumal of Psychiatry, 137, 439-444.

Bornstein, R. A., Termeer, J., Longbrake, K., Heger, M., \& North, R. (1989). WAIS-R cholinergic deficit profile in depression. Psychological Assessment: Journal of Consulting and Clinical Psychology, 1, 342-344.

Buschke, H. (1973). Selective reminding for analysis of memory and learning. Journal of Verbal Learning and Verbal Behavior, 12, 543-550.

Caine, E. D. (1981). Pseudodementia: Current concepts and future directions. Archives of General Psychiatry, 38, 1359-1364.

Caine, E. D. (1986). The neuropsychology of depression: The pseudodementia syndrome. In I. Grant \& K. Adams (Eds.), Neuropsychological assessment of neuropsychiatric disorders (pp. 221-243). New York: Oxford University Press.

Cassens, G., Wolfe, L., Zola, M. (1990). The neuropsychology of depressions. Joumal of Neuropsychiatry and Clinical Neurosciences, 2, 202-213.

Coffey, C. E., Figiel, G. S., Djang, W. T., Cress, M., Saunders, W. B., \& Weiner, R. D. (1988). Leuknencephalopathy in elderly depressed patients referred for ECT. Biological Psychiatry. 24, 143-161.

Coffey, C. E., Figiel, G. S., Djang, W. T., \& Saunders, W. B. (1989). White matter hyperintensity on magnetic resonance imaging: Clinical and neuroanatomic correlates in the depressed elderIy. Journal of Neuropsychiatry and Clinical Neurosciences, 1, 135-144.

Coffey, C. E., Figiel, G. S., Djang, W. T., \& Weiner, R. D. (1990). Subcortical hyperintensity on magnetic resonance imaging: A comparison of normal and depressed elderly subjects. American Journal of Psychiatry, 147, 187-189.

Craik, F. I. M., \& Lockhart, R. S. (1972). Levels of processing: A framework for memory research. Journal of Verbal Learning and Verbal Behavior, 11, 671-684.

Cummings, J., Benson, D. F., \& LoVerme, S. (1980). Reversible dementia, Journal of the American Medical Association, 243, 2434-2439. 
Dannenbaum, S. E., Parkinson, S. R., \& Inman, V. W. (1988). Short-term forgetting: Comparisons between patients with dementia of the Alzheimer type, depressed and normal elderly. Cognitive Neuropsychology, 5, 213-233.

Derogatis, L. R., \& Melisaratos, N. (1983). The brief symptom inventory: An introduction. Psychological Medicine, 13, 595-605.

Dolan, R. J., Calloway, S. P., \& Mann, A. H. (1985). Cerebral ventricle size in depressed subjects. Psychological Medicine, 15, 873-878.

Dolan, R. J., Calloway, S. P., Thacker, P. F., \& Mann, A. H. (1986). The cerebral cortical appearance in depressed subjects. Psychological Medicine, 16, 775-779.

Dupont, R. M., Jernigan. T. L.. Butters, N., Delis, D., Hesselink, J. R., Heindel, W., \& Gillin, C. (1990). Subcortical abnormalities detected in bipolar affective disorder using magnetic imaging. Archives of General Psychiatry, 47, 55-59.

Dupont, R. M., Jernigan, T. L., Gillin, C., Butters, N., Delis, D., \& Hesselink, J. R. (1987). Presence of subcortical signal hyperintensities in bipolar patients detected by MRI. Psychiatry Research, 21, 357-358.

Emery, O. B., \& Breslau, L. D. (1989). Language deficits in depression: Comparisons with SDAT and normal aging. Journal of Gerontology: Medical Sciences, 44, M85-M92.

Evans, D. A., Funkenstein, H. H., Albert, M. S., Scherr, P. A., Cook, N. R., Chown, M. J., Hebert, L. E., Hennekens, C. H., \& Taylor, J. O. (1989). Prevalence of Alzheimer's disease in a community population of older persons: Higher than previously reported. Journal of the American Medical Association, 262, 2551-2556.

Feinberg, T., \& Goodman, B. (1984). Affective illness, dementia, and pseudodementia. Journal of Clinical Psychiatry, 45, 99-103.

Fogel, B. S., \& Fretwell, M. (1985). Reclassification of depression in the medically ill elderly. Joumal of the American Geriatrics Society, 33, 446-448.

Folstein, M. F. \& McHugh, P. R. (1978). Dementia syndrome of depression. In R. Katzman, R. Terry \& K. Brick (Eds.), Alzheimer's disease: Senile dementia and related disorders. New York: Raven Press.

Folstein, M. F., \& Rabins, P. V. (1991). Replacing pseudodementia. Neuropsychiatry, Neuropsychology, and Behavioral Neurology, 4, 36-40.

French, L. R., Schuman, L. M., Mortimer, J. A., Hutton, J. T., Boatman, R. A., Christians, B. (1985). A case-control study of dementia of the Alzheimer type. American Journal of Epidemiology, 121, 414-421.

Fuld, P. A. (1984). Test profile of cholinergic dysfunction and of Alzheimer type dementia. Journal of Clinical Neuropsychology, 6, 380-392.

Garcia, C. A., Reding, M. J., \& Blass, J. P. (1981). Overdiagnosis of dementia. Joumal of the American Geriatrics Society, 29, 407-410.

Gatz, M., \& Hurwicz, M. (1990). Are older people more depressed? Cross-sectional data on Center for Epidemiological Studies Depression Scale factors. Psychology and Aging, 5, 284-290.

Grafton, S. T., Sumi, S. M., Stimac, G. K., Alvord, E. C., Shaw, C., \& Nochlin, D. (1991). Comparison of postmortem magnetic resonance imaging and neuropathologic findings in the cerebral white matter. Archives of Neurology, 48, 293-298.

Gray, J. W., Rattan, A. I., \& Dean, R. S. (1986). Differential diagnosis of dementia and depression in the elderly using neuropsychological methods. Archives of Clinical Neuropsychology, 1, 341-349.

Hale, W. D., Cochran, C. D., \& Hedgepeth, B. E. (1984). Norms for the elderly on the Brief Symptom Inventory. Journal of Consulting and Clinical Psychology, 52, 321-322.

Harper, R. G., Kirby, H. G., \& Kotik-Harper, D. (1986). Adequacy of conventional assessment of depression in the elderly. Gerontologist, 26, 224A.

Harper, R. G., Kotik-Harper, D., \& Kirby, H. G. (1990). Psychometric assessment of depression in an elderly general medical population: Over- or underassessment? Joumal of Nervous and Mental Disease, 178, 113-119. 
Hart, R. P., \& Kwentus, J. A. (1987). Psychomotor slowing and subcortical-type dysfunction in depression. Journal of Neurology, Neurosurgery and Psychiatry, 50, 1263-1266.

Hart. R. P., Kwentus, J. A., Hamer, R. M., \& Taylor, J. R. (1987). Selective reminding procedure in depression and dementia. Psychology and Aging, 2, 111-115.

Hart, R. P., Kwentus, J. A., Leshner, R. T., \& Frazier, R. (1985). Information processing speed in Friedreich's ataxia. Annals of Neurology, 17, 612-614.

Hart, R. P., Kwentus, J. A., Taylor, J. R., \& Hamer, R. M. (1988). Produclive naming and memory in depression and Alzheimer's type dementia. Archives of Clinical Neuropsychology, 3, 313-322.

Hart, R. P., Kwentus, J. A., Taylor, J. R., \& Harkins, S. W. (1987). Rate of forgetting in dementia and depression. Journal of Consulting and Clinical Psychology, 55, 101-105.

Hart, R. P., Kwentus, J. A., Wade, J. B., \& Hamer, R. M. (1987). Digit symbol performance in mild dementia and depression. Journal of Consulting and Clinical Psychology, 55, 236-238.

Hasher, L., \& Zacks, R. T. (1979). Automatic and effortful processes in memory. Journal of Experimental Psychology: General, 108, 356-388.

Hertzog, C., VanAlstine, J., Usala, P. D., Hultsch, D. F., \& Dixon, R. (1990). Measurement properties of the Center for Epidemiological Studies Depression Scale (CES-D) in older populations. Psychological Assessment, 2, 64-72.

Heston, L. L., \& Mastri, A. R. (1982). Age at onset of Pick's and Alzheimer's dementia: Implications for diagnosis and research. Journal of Gerontology, 37, 422-424.

Huppert, F. A., \& Piercy, M. (1978). Dissociation between learning and remembering in organic amnesia. Nature, 275, 317-318.

Jacoby, R. J., \& Levy, R. (1980). Computed tomography in the elderly: affective disorder. British Journal of Psychiatry, 136, 270-275.

Jacoby, R. J., Levy, R., \& Bird, J. M. (1981). Computed tomography and the outcome of affective disorder: a follow-up study of elderly patients. British Journal of Psychiatry, 139, 288-292.

Kahn, H. L., Zarit, S. H., Hilbert, N. M., \& Niederehe, G. A. (1975). Memory complaints and impairment in the aged: The effect of depression and altered brain function. Archives of General Psychiatry, 32, 1560-1573.

Kaplan, E. F., Goodglass, H., \& Weintraub, S. (1983). The Boston Naming Test. Philadelphia: Lea and Febiger.

Kaszniak, A. W. (1985). Personality and emotional change in dementia of the Alzheimer's type: Issues in the investigation of individual differences. Journal of Clinical and Experimental Neuropsychology, 7, 611 (abstract).

Kaszniak, A. W. (1987). Neuropsychological consultation to geriatricians: Issues in the assessment of memory complaints. Clinical Neuropsychologist, 1, 35-46.

Kaszniak, 'A. W., Poon, L. W., \& Riege, W. (1986). Assessing memory deficits: An information processing approach. In L. Poon (Ed.), Handbook for clinical memory assessment of older adults (pp. 168-188). Washington, DC: American Psychological Association.

Kaszniak, A. W., Wilson, R. S., Lazarus, L., Lessor, J., \& Fox, J. H. (1981, February). Memory and depression in dementia. Paper presented at the Annual Meeting of the International Neuropsychological Society, Aulanta, GA.

Kertesz, A., Polk, M., \& Carr, T. (1990). Cognition and white matter changes on magnetic imaging in dementia. Archives of Neurology, 47, 387-391.

Kiernan, R. J., Mueller, J., Langston, J. W., \& VanDyke, C. (1987). The Neurobehavioral Cognitive Status Examination: A brief but quantitative approach to cognitive assessment. Annals of Internal Medicine, 107, 481-485.

Kiloh, L. G. (1961). Pseudo-dementia. Acta Psychiarrica Scandinavica, 37, 336-351.

Kincannon, J. C. (1968). Prediction of the standard MMPI scale scores from 71 items: The MiniMult. Journal of consulting and Clinical Psychology, 32, 319-325.

Kral, V. A., \& Emery, O. B. (1989). Long-term follow-up of depressive pseudodementia of the aged. Canadian Journal of Psychiatry, 34, 445-446.

Kramer, M., German, P. S., Anthony, J. C., VonKorf, M., \& Skinner, E. A. (1985). Patterns of mental disorder among the elderly residents of eastern Baltimore. Journal of the American Geriatrics Society, 33, 236-245. 
La Rue, A. (1989). Patterns of performance on the Fuld Object Memory Evaluation in elderly inpatients with depression or dementia. Journal of Clinical and Experimental Neuropsychology, 11, 409-422.

La Rue, A., D'Elia, L. F., Clark, E. O., Spar, J. E., \& Jarvik, L. F. (1986). Clinical tests of memory in dementia, depression and healthy aging. Journal of Psychology and Aging, 1, 69-77.

Lazarus, L. W., Newton, N., Cohler, B., Lesser, J., \& Schweon, C. (1987). Frequency and presentation of depressive symptoms in patients with primary degenerative dementia. American Journal of Psychiatry, 144, 41-45.

Lishman, W. A. (1987). Organic Psychiatry. Oxford: Blackwell Scientific Publications.

Martin, A., \& Fedio, P. (1983). Word production and comprehension in Alzheimer's disease: The breakdown of semantic knowledge. Brain and Language, 19, 124-141.

McAllister, T. W. (1983). Overview: Pseudodementia. American Journal of Psychiatry, 140, 528-533.

McCarney, J. R. (1986). Physicians assessment of cognitive capacity: Failure to meet the needs of the elderly. Archives of Internal Medicine, 146, 177-178.

McCue, M., Goldstein, G., \& Shelly, C. (1989). The application of a short form of the LuriaNebraska Neuropsychological Battery to discrimination between dementia and depression in the elderly. International Jourmal of Clinical Neuropsychology, 11, 21-29.

Miller, E., \& Lewis, P. (1977). Recognition memory in elderly patients with depression and dementia: A signal detection analysis. Journal of Abnormal Psychology, 86(1), 84-86.

Morris, P., \& Rapoport, S. I. (1990). Neuroimaging and affective disorder in late life: A review. Canadian Journal of Psychiatry, 35, 347-354.

Myers, J. K., Weissman, M. M., Tischler, G. L., Holzer, C. E., Leaf, P. J., Orvaschel, H., Anthony, J. C., Boyd, J. H., Burke, J. D., Kramer, M., et al. (1984). Six-month prevalence of psychiatric disorders in three communities, 1980 to 1982. Archives of General Psychiatry, 41, 959-967.

National Institute on Aging Task Force (1980). Senility reconsidered: Treatment possibilities for mental impairment in the elderly. Journal of the American Medical Association, 244, 259-263.

Newmann, J. P. (1989). Aging and depression. Psychology and Aging, 4, 150-165.

Niederehe, G. (1986). Depression and memory impairment in the aged. In L. Poon (Ed.), Handbook for clinical memory assessment of older adults (pp. 226-237). Washington, DC: American Psychological Association.

Niederehe, G., \& Camp, C. J. (1985). Signal detection analysis of recognition memory in depressed elderly. Experimental Aging Research, 11, 207-213.

Nussbaum, P. D., Kaszniak, A. W., Allender, J., \& Rapesak, S. Z. (1991). Depression and cognitive deterioration in the elderly: A follow-up study. Journal of Clinical and Experimental Psychology, 13, 100.

Parmelee, P. A., Katz, I. R., \& Lawton, M. P. (1989). Depression among institutionalized aged: Assessment and prevalence estimation. Journal of Gerontology: Medical Sciences, 44, M22-M29.

Pearlson, G. D., Rabins, P. V., Kim, W. S., Speedie, L. J., Moberg, P. J., Burns, A., \& Bascom, M. J. (1989). Structural brain CT changes and cognitive deficits in elderly depressives with and without reversible dementia (pseudodementia). Psychological Medicine, 19, 573-584.

Pfeffer, R. I., Afifi, A. A., \& Chance, J. M. (1987). Prevalence of Alzheimer's disease in a retirement community. American Journal of Epidemiology, 125, 420-436.

Popkin, S. J., Gallagher, D., Thumpson, L. W., \& Moore, M. (1982). Memory complaint and performance in normal and depressed older aduits. Experimental Aging Research, 8, 141-145.

Reding, M., Haycox, J., \& Blass, J. (1985). Depression in patients referred to a dementia clinic: A three-year prospective study. Archives of Neurology, 42, 894-896.

Reifler, B. V. (1986). Mixed cognitive-affective disturbance in the elderly: A new classification. Journal of Clinical Psychiatry, 47, 354-356.

Reifler, B. V., Larson, E., Hanley, R. (1982). Coexistence of cognitive impairment and depression in geriatric outpatients. American Journal of Psychiatry, 139, 623-626. 
Risse, S. C., Raskind, M. A., Nochlin, D., \& Sumi, S. M. (1990). Neuropathological findings in patients with clinical diagnoses of probable Alzheimer's disease. American Journal of Psychiatry, 147, 168-172.

Robins, L. N., Helzer, J. E., Weissman, M. M., Orvaschel, H., Gruenberg. E., Burke, J. D., Regier, D. A. (1984). Lifetime prevalence of specific psychiatric disorders in three sites. Archives of General Psychiatry, 41, 949-958.

Ron, M. A., Toone, B. K., Garralda, M. E., \& Lishman, W. A. (1979). Diagnostic accuracy in presenile dementia. British Journal of Psychiatry, 134, 161-168.

Satz, P., VanGorp, W. G., Soper, H. V., \& Mitrushina, M. (1987). A WAIS-R marker for dementia of the Alzheimer type? An empirical and statistical induction test. Journal of Clinical and Experimental Neuropsychology, 9, 767-774.

Schnurr, R., Hoaken, P. C. S., Jarrett, F. J. (1976). Comparison of depression inventories in a clinical population. Canadian Psychiatric Association Journal, 21, 473-476.

Snowdon, J. (1990). The prevalence of depression in old age. International Journal of Geriatric Psychiatry, 5, 141-144.

Speedie, L., Rabins, P., Pearlson, G., \& Moberg, P. (1990). Confrontation naming deficit in dementia of depression. Journal of Neuropsychiatry and Clinical Neurosciences, 2, 59-63.

Spitzer, R. L., Endicoth, J., \& Robins, E. (1978). Research Diagnostic Criteria: Rationale and reliability. Archives of General Psychiatry, 35, 773-782.

Sternberg, S. (1975). Memory scanning: new findings and current controversies. Quarterly Joumal of Experimental Psychology, 27, 1-32.

Sternberg, D. E., \& Jarvik, M. E. (1976). Memory functions in depression: Improvement with antidepressant medication. Archives of General Psychiatry, 33, 219-224.

Tulving, E. (1972). Episodic and semantic memory. In E. Tulving \& W. Donaldson (Eds.), Organization of memory. New York: Academic Press.

Wechsler, D. (1981). Manual for the Wechsler Adult Intelligence Scale - Revised. Cleveland: Psychological Corporation.

Weingartner, H. (1986). Automatic and effort-demanding cognitive processes in depression. In L. Poon (Ed.), Handbook for clinical memory assessment of older adults (pp. 218-225). Washington, DC: American Psychological Association.

Weingartner, H., Cohen, R. M., Murphy, D. L., Martello, J., \& Gerdt, C. (1981). Cognitive processes in depression. Archives of General Psychiatry, 38, 42-47.

Weissman, M. M., \& Myers, J. K. (1978). Affective disorders in a U.S. urban community: The use of research diagnostic criteria in an epidemiologic survey. Archives of General Psychiatry, 35, 1304-1311.

Wells, C. E. (1979). Pseudodementia. American Journal of Psychiarry, 136, 895-900.

Welsh, K., Butters, N., Hughes, J., Mohs, R., \& Heyman, A. (1991). Detection of abnormal memory decline in mild cases of Alzheimer's disease using CERAD neuropsychological measures. Archives of Neurology, 48, 278-281.

Whitehead, A. (1973). Verbal learning and memory in elderly depressives. British Journal of Psychiatry, 123, 203-208.

Whitehead, A. (1974). Factors in the learning deficits of elderly depressives. British Journal of Social and Clinical Psychology, 13, 201-208.

Wilson, R. S., Fox, J. H., Huckman, M. S., Bacon, L. D., \& Lobick, J. J. (1982). Computed tomography in dementia. Neurology (Ny), 32, 1054-1057.

Wilson, R. S., Kaszniak, A. L., Klawans, H. L., \& Garron, D. C. (1980). High speed memory scanning in Parkinsonism. Cortex, 12, 67-72.

Yesavage, J. A., Brink, T. L., Rose, T. L., Lum, O., Huang, V., Adey, M., \& Leirer, V. O. (1983). Development and validation of a Geriatric Depression Scale. Journal of Psychiatric Research, 17, 31-49. 